
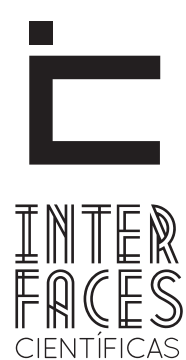

EDUCAÇÃO

ISSN IMPRESSO 2316-333X

E-ISSN 2316-3828

DOI-10.17564/2316-3828.2017v5n3p87-96

\title{
A METODOLOGIA CIENTÍFICA EM PESQUISAS EDUCACIONAIS: PENSAR E FAZER CIÊNCIA
}

\author{
THE SCIENTIFIC METHODOLOGY IN EDUCATIONAL RESEARCH: THINKING AND DOING SCIENCE \\ LA METODOLOGía CIENTíFICA EN LA INVESTIGACIÓN EDUCATIVA: PENSAR Y DE HACER CIENCIA
}

Priscilla Bibiano de Oliveira Mendonça ${ }^{1}$

\section{RESUMO}

Este artigo visa promover reflexão acerca das pesquisas em educação como processos de produção de conhecimento, trazendo pontos acerca do pensar e do fazer Ciência. Para alcançar o objetivo foi realizada revisão bibliográfica sobre o assunto. Traz o equívoco atual quanto ao desenvolvimento de pesquisas, tidas erroneamente como investigação e coleta de dados e evidencia abordagens relacionadas à pesquisa em educação. No que tange ao pensar a Ciência fala da necessidade da curiosidade epistemológica, do conhecimento e seus tipos e as finalidades da pesquisa; sobre o fazer
Ciência trata dos pressupostos, métodos e técnicas de pesquisa, mostrando suas diferentes classificações quanto à natureza, objetivos, abordagens e procedimentos - bem como apontando algumas técnicas de coleta de dados utilizadas em pesquisas educacionais.

\section{PALAVRAS-CHAVE}

Conhecimento científico. Metodologia da Pesquisa. Instrumentos de Pesquisa. 


\section{ABSTRACT}

This article aims to promote reflection on research in how processes of knowledge production, bringing points on thinking and doing Science. For the purpose of bibliographical review on the contract. It brings the current misconception about the development of research, erroneously taken as research and data collection and evidence approaches related to research in education. In what concerns to think the Science of the necessity of the epistemological curiosity, of the knowledge and its types and like aims of the research; About making science about assumptions, methods and research techniques, showing their different conditions as to nature, objectives, approaches and procedures - as well as pointing out some techniques of data collection used in educational research.

\section{KEYWORDS}

Scientific knowledge. Research methodology. Research Tools.

\section{RESUMEN}

Este artículo tiene como objetivo promover la reflexión acerca de la investigación en educación como proceso de producción de conocimiento, discutiendo el pensar y hacer ciencia. Para alcanzar objetivo, se realizó revisión de literatura acerca del tema. Abarca el error actual sobre el desarrollo de la investigación, erróneamente considerado como enfoques de investigación y recopilación de datos y resalta los planteamientos relacionadas con la investigación en la educación. Cuando se trata de la necesidad de pensar en la ciencia, se trata de la curiosidad epistemológica, del conocimiento y sus tipos y los fines de investiga- ción; Acerca de hacer ciencia, debaten los supuestos, métodos y técnicas de investigación, mostrando sus diferentes condiciones de la naturaleza, objetivos, enfoques y procedimientos -, así como señalar algunas técnicas de recolección de datos utilizados en la investigación educativa.

\section{PALABRAS CLAVE}

Conocimiento científico. Metodología de la investigación. Instrumentos de investigación. 


\section{INTRODUCÇÃO}

O ser humano é, por constituição, curioso; ou seja, ele quer conhecer o mundo que o cerca e se apropriar dele. Esse se debruçar sobre o mundo é aprimorado frente ao que chamamos de curiosidade epistemológica, uma curiosidade que ousa ir além do senso comum, buscando se apropriar do que desafia e instiga em determinadas situações, baseada em conhecimentos científicos.

Os conhecimentos científicos são inseridos na vida humana desde muito cedo quando a criança ingressa na escola e vai realizando processos de experimentação mediante os desafios que lhe são apresentados. Essa é uma época em que a capacidade de perguntar, de questionar o mundo está em evidência. Com o passar dos anos, a criança é apresentada ao mundo da pesquisa, espera-se que ela consiga por si só, construir suas impressões acerca da realidade; e também gerar novos conhecimentos.

Aí começa um grande desafio para a educação em todos os níveis, deixar que o estudante refaça caminhos já percorridos por outros, mas, ao mesmo tempo, ter autonomia de pensamento e construção de novas ideias. Esse processo é permeado de encanto e de fragilidades. Ao mesmo tempo em que os professores introduzem os estudantes no mundo da busca eles podem criar o embotamento da inteligência. Isso porque, infelizmente, a pesquisa tem sido encarada como coleta de informações; a pesquisa deixa de ter seu caráter de desconstruir para reconstruir com significado (desconstruir no sentido de esmiuçar o objeto a ser pesquisado). Os estudantes copiam dados em diferentes contextos, porém não refletem, não constroem algo novo acerca do que foi investigado.

Esse processo acaba sendo de inteligência às avessas, visto gerar indivíduos que não pensam sozinhos, tornam-se incapazes de desconfiar daquilo que veem, e perdem a beleza da dúvida, que possibilita a busca e gera aprendizagem. Muitas vezes isso acontece por desconhecimento dos educadores quanto a conceitos e metodologias de pesquisa.

Nesse sentido, esse artigo propõe retomar conceitos de pesquisa e metodologia científica, sendo relevante refletir sobre o pensar a Ciência e o fazer Ciência. Para alcançar o objetivo realizou-se revisão bibliográfica sobre o assunto, buscando articular as ideias de diversos autores que tratam da temática, como Bernadete Gatti, Heraldo Vianna, Marli André, entre outros. No que tange ao pensar a Ciência se fala da necessidade da curiosidade epistemológica, do conhecimento e seus tipos e as finalidades da pesquisa; sobre o fazer Ciência trata dos pressupostos, métodos e técnicas de pesquisa, apontando suas diferentes classificações quanto à natureza, objetivos, abordagens e procedimentos - bem como apontando algumas técnicas de coleta de dados utilizadas em pesquisas educacionais.

\section{PENSAR A CIÊNCIA}

Para pensar a Ciência é inevitável que tratemos de conhecimento e das finalidades da pesquisa, aqui entendida como processo de construção da $\mathrm{Ci}$ ência. A área da filosofia que investiga a natureza do conhecimento é a epistemologia. Para Chizzotti (2003), citado por Martins (2014), essa ciência traz como questão central o que é conhecer, quais fundamentos garantem realmente que aquilo que se pensa ser é realmente conhecimento. Nesse sentido, é importante considerar que, se a curiosidade gera a busca, a curiosidade quando se torna epistemológica gera conhecimento.

Existem diferentes tipos de conhecimento e todos eles buscam explicar a realidade, cada um à sua maneira. Traz-se as ideias de Trujillo, que é citado por Marconi e Lakatos (2003, p. 77) que sistematiza o conhecimento em quatro tipos e descreve suas características: 


\begin{tabular}{c|c|c|c}
\hline $\begin{array}{c}\text { Conhecimento } \\
\text { Popular }\end{array}$ & $\begin{array}{c}\text { Conhecimento } \\
\text { Científico }\end{array}$ & $\begin{array}{c}\text { Conhecimento } \\
\text { Filosófico }\end{array}$ & $\begin{array}{c}\text { Conhecimento } \\
\text { Religioso }\end{array}$ \\
\hline Valorativo & Real (factual) & Valorativo & Valorativo \\
\hline Reflexivo & Contingente & Racional & Inspiracional \\
\hline Assistemático & Sistemático & Sistemático & Sistemático \\
\hline Verificável & Verificável & Não verificável & Não verificável \\
\hline Falível & Falível & Infalível & Infalivel \\
\hline Inexato & $\begin{array}{c}\text { Aproximadamente } \\
\text { exato }\end{array}$ & Exato & Exato \\
\hline
\end{tabular}

Quadro 1 - Tipos e características do conhecimento

Importa-nos neste trabalho, o conhecimento científico e o modo como ele é operacionalizado, ou seja, sua metodologia. Minayo (2003), citada por Martins (2014), afirma que a metodologia inclui um método, as técnicas e a criatividade do pesquisador. Martins alerta-nos também que todo esse processo é permeado de crenças, leituras de mundo sobre a realidade, concepções teóricas, ou seja, de paradigmas; e mais, que esses paradigmas guiarão o método de pesquisa a ser adotado daí a importância da conscientização quanto a eles. Para essa autora,

As pesquisas na área de educação não fogem a essa premissa e não podemos ignorar as referências paradigmáticas que as orientam. [...] Vários autores e estudiosos da epistemologia na área das ciências humanas aglutinam os paradigmas em dois grupos de abordagem: quantitativo e qualitativo. (MARTINS, 2010, p. 9).

É importante tratar da diferenciação entre essas duas modalidades de ciência tendo em vista que, mediante seus objetivos, mudam-se também as metodologias de pesquisa. Martins (2014) traz que as ciências naturais, dizem respeito aos acontecimentos da realidade natural, de existência concreta, com objetos físicos - tem por objeto de pesquisa as coisas; já as ciências da ação humana, envolvem o humano em seu sentido mais complexo, percebendo sua constante mutação e interação - tendo por objeto as ideias.

Ainda para esse autor, os focos diferenciados de investigação geram metodologias e abordagens diferenciadas. No caso das ciências naturais, a abordagem mais comum é a quantitativa, trabalhando com variáveis e medidas, ambas controláveis ou passíveis de verificação direta e experimental. Nas pesquisas em ciências humanas, mais especificamente em educação, a abordagem mais utilizada é a qualitativa; que pretende interpretar em vez de mensurar, pensa mais em termos de compreensão da realidade e dos sujeitos. Essas especificidades traduzem formas diferentes de conceber e de produzir conhecimentos.

Ao longo dos anos aconteceram mudanças no cenário da pesquisa educacional, como a ampliação e diversificação dos temas, enfoques e, consequentemente, as abordagens metodológicas. Nesse contexto de mudança, Marli André (2007) afirma que ganham forças os estudos qualitativos que englobam um grupo heterogêneo de métodos, técnicas e análises. Os contextos de produção também se alteraram, sendo o cotidiano da escola e da sala de aula as principais preocupações dos pesquisadores.

Quanto às finalidades da pesquisa a autora aponta que urge repensar sobre o caráter pragmático que a envolve, que gera inclusive uma supervalorização da prática em detrimento da teoria. Sobre isso afirma que

[...] difícil é conciliar os papéis de ator e de pesquisador, buscando o equilíbrio entre a ação e a investigação, pois o risco é sempre muito grande de sucumbir ao fascínio da ação, deixando para segundo plano a busca do rigor que qualquer tipo de pesquisa requer. (ANDRÉ, 2007, p. 124).

Não podemos também desconsiderar que, embora a pesquisa não possa estar a serviço de solucionar os pequenos impasses do dia a dia, é importante sua aplicabilidade e impacto social.

\section{FAZER CIÊNCIA}

Após pensar acerca da curiosidade, do conhecimento e da finalidade de se pesquisar é imprescindível falarmos do fazer ciência - um processo permeado por pressupostos, métodos e técnicas. Os pressupostos teóricos determinarão os métodos e as técnicas de pesquisa, coerentes com suas crenças os pesquisadores farão opções metodológicas que respondam aos seus questionamentos e objetivos de pesquisa. Esses 
pressupostos dizem respeito aos paradigmas adotados segundo as visões de mundo de cada pesquisador.

As pesquisas podem ser classificadas de diversos modos, Vianna (2013) sintetiza essa classificação, apontando quatro tipos:

1. Quanto à natureza: define se a pesquisa será sem (básica1) ou com aplicação imediata (aplicada);

2. Quanto aos objetivos: a pesquisa pode ser exploratória (obter mais informações sobre o assunto investigado), descritiva (registra e descreve os fatos observados sem interferir neles) ou explicativa (explica as causas, valendo-se do registro, da análise, da classificação e interpretação dos fenômenos observados);

3. Quanto à abordagem: será tratada de modo qualitativo ou quantitativo;

4. Quanto aos procedimentos: documental, bibliográfica, experimental, levantamento (survey), pesquisa de campo, etnografia, estudo de caso, pesquisa-ação, pesquisa participante, pesquisa ex-post-facto.

Essa classificação auxilia o pesquisador a traçar os rumos, a nortear a construção do conhecimento a que se propôs debruçar. Aqui trataremos mais especificamente de pesquisa em educação e da classificação quanto à abordagem e quanto aos procedimentos.

\section{QUANTO À ABRODAGEM: QUALITATIVA E QUANTITATIVA}

A tradição da investigação qualitativa em educação teve suas origens no século XIX, a partir da necessidade de investigação social acerca das condições

1 Embora não tenha aplicação imediata, a pesquisa básica é primordial já que estabelece novos conhecimentos a serem utilizados em outras pesquisas. degradadas da vida urbana na sociedade americana - a expressão investigação qualitativa veio a ser utilizada com essa terminologia somente nos anos $60^{2}$. Segundo Bodgan e Biklen (1994, p. 23), "os levantamentos sociais têm uma importância particular para a compreensão histórica acerca da investigação qualitativa, devido a sua relação imediata com os problemas sociais - situando-se entre a narrativa e o estudo científico". Esse contexto histórico é importante pois lança as bases de um tempo em que as pesquisas visavam explicar a vida em seu sentido mais humano e entendiam que os números (utilizados em pesquisas qualitativas) não davam conta da amplitude e profundidade dos acontecimentos. Martins (2014) faz referência a Minard (2010) para quem as pesquisas qualitativas preocupam-se com um nível da realidade que não pode ser mensurado e quantificado.

Os autores Bodgan e Biklen (1994, p. 47), pensando em termos das características desse tipo de investigação apontam que:
1. 0 ambiente natural é a fonte direta de dados e o ins- trumento principal é o investigador;
2. É descritiva;
3. Interessa-se mais pelo processo que do simples- mente os produtos ou resultados;
4. Os dados tendem a ser analisados de forma indutiva; 5. O significado é de importância vital na abordagem qualitativa.

Essas características se traduzem na preocupação do pesquisador quanto ao contexto em que se insere a pesquisa, em registrar os fatos tais como são, não visar produtos e sim processos - por isso abordam o mundo de forma minuciosa. Além disso, a análise dos dados é vista como um funil (BODGAN; BIKLEN, 1994, p. 50), "as coisas estão mais abertas no topo e vão se tornando mais fechadas e específicas no extremo". As abordagens qualitativas permitem explicar acontecimentos sociais e comportamento humano.

Outra possibilidade de pesquisa em educação é a abordagem quantitativa que, embora não seja a mais

2 É importante referenciar a Escola de Chicago, que nos anos 1920 e 1930 muito contribuiu para o desenvolvimento da abordagem qualitativa de pesquisa. 
utilizada quando se trata das ciências sociais, é uma maneira de explorar determinada realidade ou fato; poderíamos comparar o método com uma lupa em meio a uma massa de dados. Para Gatti (2004, p. 13), "é necessário pensar que os números, frequências, medidas, têm algumas propriedades que delimitam as operações que se podem fazer com eles; e que as boas análises dependem de boas perguntas que o pesquisador venha a fazer".

Nesse sentido cabe refletirmos que o sucesso dos estudos quantitativos está na abordagem do pesquisador acerca do que se coletou, ou seja, a grande utilidade dos métodos quantitativos está em analisá-los para além dos dados, trazê-los como instrumento de reflexão acerca de um determinado contexto.

O modo de obtenção de quantificações dependerá da natureza do objeto, dos objetivos do investigador e do instrumento de coleta. Gatti (2004, p. 14) aponta três tipos de dados: categóricos, ordenados e métricos; e afirma que para cada um deles há possibilidades de tratamentos específicos, como podemos ver a seguir:

- Categoriais - podemos colocar em classificações e verificar sua frequência nas classes;

- Ordenados - quando estão numa forma que mostra sua posição relativa segundo alguma caraterística; mas que não há associação de um valor numérico para essa característica, nem um intervalo regular entre uma posição e outra;

- Métricos - observações relativas a características que podem ser mensuradas e expressas numa escala numérica.

É válido considerar que o procedimento quantitativo ${ }^{3}$ insere grau de validade racional no confronto com os fenômenos observados:

Estas análises, a partir de dados quantificados, contextualizadas por perspectivas teóricas, com escolhas

3 Requer o uso de recursos e técnicas de estatística, procurando traduzir em números os conhecimentos gerados pelo pesquisador (VIANNA, 2013). metodológicas cuidadosas, trazem subsídios concretos para a compreensão de fenômenos educacionais indo além dos casuísmos e contribuindo para a produção / enfrentamento de políticas educacionais, para planejamento, administração / gestão da educação, podendo ainda orientar ações pedagógicas de cunho mais geral ou específico. (GATTI, 2004, p. 26).

O cunho filosófico, os paradigmas que fundamentam as visões de mundo de cada pesquisador é que darão a significação às metodologias, sejam elas qualitativas ou quantitativas.

\section{QUANTO AOS PROCEDIMENTOS}

Após definida a abordagem da pesquisa, o pesquisador precisa se concentrar nos procedimentos técnicos que utilizará. Esses procedimentos precisam estar em consonância com os objetivos da pesquisa, caso contrário, o pesquisador não terá seus questionamentos respondidos. Referente à classificação apontada por Vianna (2013, p. 1), a pesquisa quanto aos procedimentos pode ser:

- Documental - baseia-se em materiais que não receberam ainda um tratamento analítico;

- Bibliográfica - coloca o pesquisador em contato com as publicações existentes acerca de determinado assunto (livros, revistas, periódicos e artigos científicos, jornais, boletins, monografias, dissertações, teses, material cartográfico, internet) e deve dar destaque à veracidade das fontes e dados, observando possíveis incoerências;

- Experimental - estabelece um objeto de estudo e observa as variáveis que influem nos fenômenos, tem como objetivo demonstrar como e por que determinado fato é produzido;

- Levantamento (survey) - envolve a interrogação direta a um grupo de pessoas cujo comporta- 
mento está sendo pesquisado;

- Pesquisa de campo - é a observação de fatos e fenômenos espontâneos, geralmente in loco;

- Etnografia - visa realizar a descrição dos significados pertencente a um determinado grupo ou fenômeno social particular;

- Estudo de caso - consiste em coletar e analisar informações sobre determinado indivíduo, um grupo ou comunidade, a fim de estudar aspectos variados que sejam objeto da pesquisa;

- Pesquisa-ação - concebida e realizada para a resolução de um problema coletivo, os pesquisadores e os participantes representativos da situação ou do problema estão envolvidos de modo cooperativo ou participativo;

- Pesquisa participante - desenvolvida com a participação de grupos de pesquisa e/ou pesquisadores individuais em situações investigadas similares, caracteriza-se pela interação entre os membros;

- Ex-post-facto - "uma investigação sistemática e empírica na qual o pesquisador não tem controle direto sobre as variáveis independentes, porque já ocorreram suas manifestações ou porque são intrinsecamente não manipuláveis" (Gil, 2008), busca-se saber quais os possíveis relacionamentos entre as variáveis.

Cada um desses procedimentos é capaz de responder a objetivos específicos em pesquisas. Os procedimentos podem ter características qualitativas ou quantitativas. 0 estudo de caso é um procedimento que pode ser visto como qualitativo.

Alves-Mazzotti (2006) cita como estudiosos dessa área Robert Stake, posicionando-o como mais afinado com o construcionismo social, e Robert Yin, com o pós-positivismo. Embora divergentes em vários pontos, ambos afirmam que o estudo de caso qualitativo constitui uma investigação de uma unidade específica, situada em seu contexto, selecionada segundo critérios predeterminados e, utilizando múltiplas fontes de dados, que se propõe a oferecer uma visão holística do fenômeno estudado. E é por conta dessa perspectiva holística que estudos de caso são tão utilizados em pesquisas educacionais.

A mesma autora (2006, p. 639) aponta os usos e abusos desse procedimento, afirmando que o maior problema de grande parte dos trabalhos apresentados como estudos de caso é que eles não se caracterizam como tal. Talvez o maior desses equívocos resida na afirmação de que os estudos de caso são um tipo de pesquisa mais fácil, pelo fato de lidar com uma ou poucas unidades. Para Alves-Mazzotti (2006, p. 648),

\begin{abstract}
Nem todo estudo de uma única unidade pode ser considerado um estudo de caso, e estudos de caso não são fáceis de serem realizados, ao contrário, eles se revestem de grande complexidade, o que exige o recurso a técnicas variadas de coleta de dados.
\end{abstract}

Como exemplo de procedimento quantitativo, trazemos o survey, que é definido segundo Silva (1997), mencionado por Vasconcelos e Guedes (2014), como coleta sistemática de informações a partir dos respondentes com o propósito de compreender e/ou prever alguns aspectos do comportamento da população em estudo. Esse procedimento é operacionalizado via questionário autopreenchido, entrevista pessoal ou entrevista por telefone. Mattar (1999), referenciado em Vasconcelos e Guedes (2014), salienta que os critérios para decidir a forma de utilizar o instrumento são muitos, como por exemplo: o tipo de pesquisa, o tipo de respondente (nível educacional e social), o assunto, a disponibilidade de meios para administrar a pesquisa (incluindo a qualidade do funcionamento e o acesso ao público pesquisado) e o tipo de análise e interpretação pretendidas.

Os procedimentos de pesquisa, por sua vez, são operacionalizados por meio das técnicas de coleta de dados, efetivadas por meio de instrumentos que trarão os dados a serem analisados pelo pesquisador. Podemos citar como técnicas de coleta de dados o questionário, a entrevista, a observação, o grupo focal. 
Na visão de Vianna (2003), as técnicas de observação em pesquisa são, praticamente, as únicas abordagens disponíveis para o estudo de comportamentos complexos; acreditando que os fenômenos educacionais são, em sua maioria, complexos, a observação é, então, um procedimento eficaz para estudá-los. Para Selltiz e outros autores (1967), citados por Vianna (2003, p. 20), a observação deve levar em consideração o que deve efetivamente ser observado, como proceder para efetuar o registro dessas observações, quais os procedimentos a utilizar para garantir a validade das observações e que tipo de relação estabelecer entre o observador e o observado, qual a sua natureza e como implementar essa relação.

A observação, como técnica científica, pressupõe a realização de uma pesquisa com objetivos criteriosamente formulados, planejamento adequado, registro sistemático de dados, verificação de validade de todo o desenrolar do seu processo e confiabilidade dos resultados. (VIANNA, 2003, p. 14).

Embora a observação seja imprescindível para se conhecer fatos / fenômenos, é importante atentar para alguns problemas decorrentes desse procedimento, tais como, influência da presença do observador e alto investimento de tempo, de permanência. Além do que, em se tratando de observação, nem sempre se encontra pessoas dispostas a serem sujeitos de um estudo observacional, nesse sentido, o poder de persuasão do observador deve ser grande. Devido ao tempo da observação, pode ocorrer relacionamento emocional com o observado, o que pode facilitar ao dificultar a observação.

Bailey (1994) tem seus argumentos sobre as fases da observação apresentados no livro de Vianna (2003, p. 30), sendo elas:

- Definir os objetivos do estudo;

- Decidir sobre o grupo de sujeitos a observar;

- Legitimar sua presença junto ao grupo a observar;

- Obter confiança dos sujeitos a observar;

- Observar e registrar notas de campo durante semanas;

- Gerenciar possíveis crises que possam ocorrer entre os sujeitos e o observador;
- Saber retirar-se do campo de observação;

- Analisar os dados;

- Elaborar um relatório sobre os elementos obtidos.

A análise dos dados e a elaboração dos relatórios são fases importantes do processo de observação. Para que os dados levantados sejam mais convincentes, é recomendável que o observador faça uma triangulação da observação. A triangulação consiste em trazer outras fontes e dados coletados (até mesmo por outros pesquisadores), o que dará maior consistência à pesquisa. Outro ponto importante da observação é a redução de dados, já que é impossível observar a tudo. A análise categorial dos dados é uma possibilidade de classificação por posicionamentos, tempo de ocorrência ou frequência dos eventos. É necessário decidir o que vai ser quantificado.

Salienta-se a necessidade de fundamentos teóricos consistentes relacionados à natureza dos fatos observados, além da apuração do olhar do observador a fim de identificar e descrever coerentemente os diversos tipos de interação e processos humanos. Além disso, deve-se dar atenção ao não-verbal, aquilo que fica nas entrelinhas da observação.

\begin{abstract}
Cabe ressaltar que o observador não se deve concentrar apenas naquilo que lhe convém para justificar suas formulações e hipóteses teóricas, mas registrar também outros pontos que podem, inclusive, contradizer o arcabouço teórico que o construiu. (VIANNA, 2003, p. 89).
\end{abstract}

Esse autor, trazendo a observação para o contexto da escola, apresenta alguns elementos importantes a serem considerados pelo pesquisador: traços pessoais nas relações, interação verbal, elementos não-verbais, atividades, gerenciamento, habilidades profissionais, auxílios ao ensino, características afetivas, aspectos cognitivos, traços sociológicos. Por aí percebemos que as abordagens quantitativas procuram ir além da superfície dos eventos, buscam determinar significados, muitas vezes ocultos, interpretá-los, explicá-los e analisar o impacto na vida em sala de aula.

Outro ponto que acreditamos ser essencial abordar quanto aos procedimentos da pesquisa é a entrevista, uma 
técnica de coleta de dados utilizada na captação de dados subjetivos - pode ser estruturada, semiestruturada, aberta, com grupos focais, história de vida e projetiva. Boni e Quaresma (2005) apontam que as entrevistas aberta e semiestruturada têm como vantagem a flexibilidade de duração, permitindo cobertura mais profunda e respostas mais espontâneas. Por meio da entrevista é possível investigar aspectos valorativos e afetivos que determinam significados pessoais das atitudes e comportamentos humanos.

Essas mesmas autoras citam Bordieu (1999, p. 76), para quem o pesquisador deve fazer de tudo para diminuir a violência simbólica que é exercida por ele. Sugerem que durante a entrevista o pesquisador envie sinais de entendimento e estímulo ao entrevistado, levando em conta que estará convivendo com sentimentos, afetos pessoais, fragilidades. Atitudes como essa demonstram respeito pela pessoa pesquisada, criando uma atmosfera amistosa e de confiança.

É válido ressaltar que é preciso que o pesquisador tenha domínio sobre as questões que serão tratadas na entrevista, bem como consiga transcrever adequadamente o que o entrevistado falou e sentiu. É necessário ter cuidado também com a coerência entre as perguntas a serem feitas e os objetivos da pesquisa.

\section{CONSIDERAÇÕES FINAIS}

Como pudemos ver ao longo do texto, a pesquisa necessita de rigor e organização se pretende sair do senso comum, da simples captação de informações, e se tornar conhecimento científico. 0 pesquisador precisa delinear sua pesquisa para alcançar o que deseja, esse delineamento tem a ver com suas perspectivas de mundo, de sociedade, de construção de conhecimento; capacidade intelectual e criatividade são importantes nesse processo de traçar rotas. Esse desenho metodológico deve estar alinhado à natureza e aos objetivos específicos da pesquisa. A partir daí o pesquisador deve optar pelas abordagens e procedimentos que melhor responderão o que se pretende, precisa também escolher as técnicas e instrumentos de coleta de dados que utilizará.
Vimos que a pesquisa em educação tem por objetivo o estudo investigativo dos fenômenos educacionais e que, na maioria das vezes, a abordagem qualitativa é a que melhor corresponde ao que se espera - já que possibilita um olhar holístico e aprofundado ante ao comportamento humano. Isso não significa que a abordagem quantitativa não deva ser adotada, ambas podem ser utilizadas concomitantemente e de modo complementar.

O pensar e fazer Ciência caminham juntos, enquanto um lança as bases e a necessidade de novos conhecimentos e suas finalidades, o outro se apresenta como método de efetivação desse desejo de inovação frente aos desafios da modernidade. Esse processo de pensar e fazer Ciência, aqui denominado pesquisa científica, necessita de registro sistematizado e deve ser comunicado para cumprir sua função social na construção de novos conhecimentos, ou seja, além de pensar e fazer Ciência cabe também escrever Ciência, tópico a se abordar em outro trabalho.

\section{REFERÊNCIAS}

ALVES-MAZZOTTI, A.J. Usos e abusos do estudo de caso. Cadernos de Pesquisa, v.36, n.129, p.637-651, set-dez. 2006. Disponível em: <http://www.scielo.br/pdf/cp/ v36n129/a0736129.pdf>. Acesso em: 9 nov. 2014.

ANDRÉ, M. Questões sobre os fins e sobre os métodos de pesquisa em Educação. Revista Eletrônica de Educação, São Carlos, SP: UFSCar, v.1, n.1, p.119-131, set. 2007. Disponível em: <http:// www.reveduc.ufscar.br/index.php/reveduc/article/ viewFile/6/6>. Acesso em: 9 nov. 2014.

\section{BOGDAN, R.C.; BIKLEN, S.K. Investigação}

qualitativa em educação. Trad. Maria João Alvarez. Portugal: Porto, 1994. p.15 a 51.

BONI, V.; QUARESMA, S.J. Aprendendo a entrevistar, como fazer entrevistas em Ciências Sociais. Revista Eletrônica dos Pós-Graduandos em Sociologia 
Política da UFSC, v.2, n.1 (3), p.68-80, jan-jul. 2005. Disponível em: <https://periodicos.ufsc.br/index. php/emtese/article/viewFile/18027/16976>. Acesso em: 9 nov. 2014.

GATTI, B.A. Estudos quantitativos em educação.

Educação e Pesquisa, São Paulo, v.30, n.1, p.11-30, jan-abr. 2004. Disponível em: <http://www.scielo.br/ pdf/ep/v30n1/a02v30n1.pdf>. Acesso em: 9 nov. 2014.

\section{MARCONI, M.A.; LAKATOS, E.M. Fundamentos de}

metodologia científica. 5.ed. São Paulo: Atlas, 2003. p.77.

\section{MARTINS, R.X.; RAMOS, R. Reflexões sobre a produção do conhecimento e a pesquisa em educação. Disponível em: <http://avancar.ufla.br/} $\mathrm{ava} / \mathrm{mod} / \mathrm{resource} / \mathrm{view}$. php?id=6898>. Acesso em: 1 set. 2014. 14p.
VASCONCELLOS, L.; GUEDES, L.F.A. E-Surveys: vantagens e limitações dos questionários eletrônicos via internet no contexto da pesquisa científica. Disponível em: <http://www.ead.fea. usp.br/Semead/10semead/sistema/resultado/ trabalhosPDF/420.pdf >. Acesso em: 9 nov. 2014.

VIANNA, C.T. Classificação das pesquisas científicas - Notas para os alunos. Florianópolis, 2013, 2p.

Disponível em:

<http://pt.slideshare.net/cleversontabajara1/ metodologia-cientfica-tipos-de-pesquisa-ultimate>. Acesso em: 29 set. 2014.

VIANNA, H.M. Pesquisa em educação: a observação. Brasília: Plano, 2003. p.9-107. 